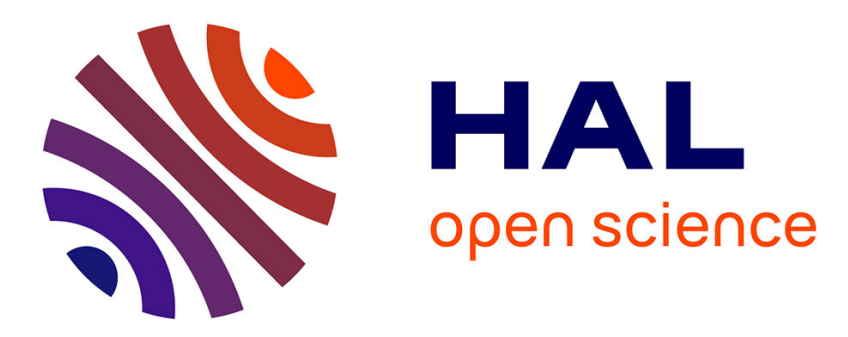

\title{
Diagnosis on Energy and Sustainability of Reconfigurable Manufacturing System (RMS) Design: A Bi-level Decomposition Approach
}

Amirhossein Khezri, Hichem Haddou Benderbal, Lyes Benyoucef, Alexandre Dolgui

\section{To cite this version:}

Amirhossein Khezri, Hichem Haddou Benderbal, Lyes Benyoucef, Alexandre Dolgui. Diagnosis on Energy and Sustainability of Reconfigurable Manufacturing System (RMS) Design: A Bi-level Decomposition Approach. 2020 IEEE International Conference on Industrial Engineering and Engineering Management (IEEM), Dec 2020, Singapour, Singapore. 10.1109/IEEM45057.2020.9309742 . hal-03131857

\section{HAL Id: hal-03131857 \\ https://hal.science/hal-03131857}

Submitted on 4 Feb 2021

HAL is a multi-disciplinary open access archive for the deposit and dissemination of scientific research documents, whether they are published or not. The documents may come from teaching and research institutions in France or abroad, or from public or private research centers.
L'archive ouverte pluridisciplinaire HAL, est destinée au dépôt et à la diffusion de documents scientifiques de niveau recherche, publiés ou non, émanant des établissements d'enseignement et de recherche français ou étrangers, des laboratoires publics ou privés. 


\title{
Diagnosis on Energy and Sustainability of Reconfigurable Manufacturing System (RMS) Design: A Bi-level Decomposition Approach
}

\author{
Amirhossein Khezri ${ }^{1}$, Hichem Haddou Benderbal ${ }^{2}$, Lyes Benyoucef $^{3}$, Alexandre Dolgui $^{2}$ \\ ${ }^{1}$ Laboratoire de Conception, Fabrication, Commande (LCFC), Arts et Métiers ParisTech, Metz, France \\ amir_hossein.khezri@ensam.eu \\ ${ }^{2}$ IMT Atlantique, LS2N-CNRS, Nantes, France \\ \{hichem.haddou-ben-derbal,alexandre.dolgui\}@imt-atlantique.fr \\ ${ }^{3}$ Aix-Marseille University, University of Toulon, CNRS, LIS, Marseille, France \\ lyes.benyoucef@lis-lab.fr
}

\begin{abstract}
Sustainability and energy consumption awareness led industrial sector to reduce energy consumption. This reduction is regarded as a solution to reduce greenhouse gas emissions. Moreover, international regulations about maintenance activities involve hazardous energy-any electrical, mechanical, nuclear or other energies that can harm personnel- as a rising threat. Thus, energy audits and diagnosis of existing manufacturing systems are crucial to achieve energy efficiency. Future manufacturing paradigms as reconfigurable manufacturing system (RMS) have shown high responsiveness to cope with new challenges such as sustainability. This paper proposes a sustainable RMS design through process plan generation. The approach is developed to generate a process plan while diagnosing energy flow and assigning preventive maintenance activities related to reliability reduction in system components. More specifically, a mixed-integer non-linear program is proposed, then solved using a bi-level decomposition approach. The lower-level considers process plan generation following parts requirements and guided by energy loss as an objective. Afterwards, the upper-level diagnoses the reliability of the lower-level selected machines and tools. Moreover, it checks if preventive maintenance is required due to the level of hazardous energy and maintenance plan. The approach applicability is validated through an illustrative example.
\end{abstract}

Keywords: Reconfigurable manufacturing system, Diagnosability, Sustainability, Process planning, Bi-level decomposition optimisation

\section{INTRODUCTION}

Nowadays, manufacturing environments are becoming more and more intelligent. This trend can be associated with the fast evolution of data acquisition technologies and the continuous and rapid progress of virtual technologies. Moreover, the current economic environment, marked by an increasingly personalized and volatile demand, led many companies to look for new forms of changeability (including flexibility and reconfigurability). In this kind of modern environment, it is crucial to have manufacturing systems with great adaptability. Besides, these systems must be characterized by responsiveness and customization.

Additionally, designing modern manufacturing systems integrates other major objectives. Amongst these objectives, 'improving productivity', 'reducing inaccuracies' and 'reducing waste' [1] as well as 'sustainability' can be found [2,3]. Environmental requirements are becoming increasingly strong, thus ensuring the sustainability of these industries is also a priority - as stressed by The Global Warming Policy Foundation (GWPF) - [4]. Thus, manufacturing systems must be more flexible, robust, reconfigurable and sustainable. Researchers like [5] stressed that "manufacturing systems must optimise the entire system and its processes to achieve sustainability". Therefore, new challenges emerged that are changeability and sustainability.

Developed during the mid-nineties by Koren, reconfigurable manufacturing system (RMS) combines the flexible manufacturing system (FMS) high flexibility with the dedicated manufacturing system (DMS) high productivity [6]. It is believed to be one of the most appropriate paradigms with the requirements of sustainability. This is possible due to its six key characteristics namely modularity, integrability, customization, convertibility, scalability, and diagnosability. Diagnosability represents the ability of the RMS to automatically read the system current state and diagnose it in order to detect the root causes of system failure and error, and subsequently correct them quickly. It can be exploited to achieve the sustainability of RMS from an energy point of view. In this context, this paper proposes an attempt to integrate diagnosability and sustainability to design a sustainable RMS (SRMS). The SRMS design is based on bi-level decomposition approach that uses process plan generation. The approach is developed to generate process plans while diagnosing energy flow and assigning preventive maintenance activities related to reliability reduction in system components.

The rest of the paper is structured as follows: Section II reviews some research works focusing on RMS design, sustainability and energy diagnosis. Section III presents the mathematical formulation and assumptions considered. Section IV details the proposed bi-level decomposition approach. Section V demonstrates an illustrative numerical example proposed. Finally, Section VI concludes the paper with some future work directions.

\section{RELATED WORKS}

As an emerging paradigm, RMS is well known for its responsiveness to the recent dynamic environments. RMS 
led to the emergence of new challenges issues as well as many new aspects, which make it an active research topic. Nevertheless, in this section, we briefly review some research works that focus on RMS design, sustainability and Energy diagnosis.

In the context of RMS design, [8] presented a novel decision support tool in reconfigurable machining systems. The authors ensured a cost-effective solution for production of several part families. [9] outlined a multiobjective approach to optimise the RMS design. Authors developed a modularity-based multi-objective approach while considering completion time and system cost.

Other authors argued the importance of integrating sustainability from the outset of the design process. [10] argued that RMS level of sustainability is an important aspect to be investigated. In the same context, [11] tackled a multi-objective sustainable process plan generation problem. Authors integrated greenhouse emissions as guiding metric. [12] proposed an environmental oriented multi-objective problem for an RMS. They proposed a weighted goal programming approach based on three objectives namely the minimization of total production time, the total production cost and the amount of environmental hazardous wastes.

Other studies like [13], analysed the benefits achieved under various energy efficiency measures from energy audits while energy efficiency improvised. An energy audit tool was developed for analysing energy flow and assessing energy saving opportunities. [14] presented a novel evaluation index system with three layers and 10 indices. The machine energy efficiency was calculated by a prediction method proposed based on recursive variable forget-ting factor identification. [15] performed a diagnosis of the energy efficiency of the ferrous and nonferrous metal casting industrial sector. Authors aimed at selecting the best proposals for the energy efficiency program in the metal casting sector. Among the more recent works, [16] proposed developed Resources Value Mapping method that aims to map and classify activities related energy/resource consumption (value-added, nonvalue-added, waste). [17] considered a process planning problem in an RMS. An $\varepsilon$-constraint method applied to minimize total time, cost, and energy consumption of changes in different level of assignments of machine, configuration, and tool. [18] developed an environmental oriented multi-objective optimisation approach in an RMS. Authors introduced a sustainability metric value covering liquid hazardous waste, greenhouse gas emissions, and energy consumption.

From our literature review analyses, and to the best of our knowledge, a dearth of research works can be observed when it comes to integrate sustainability within diagnosability in an RMS. In this context, this work proposes a first attempt from an energy flow point of view, to integrate sustainability and diagnosability aspects.

\section{PROBLEM DESCRIPTION AND FORMULATION}

\section{A. Problem description}

This paper addresses the multi-unit process planning generation problem for a single-product type in a reconfigurable manufacturing environment. It is considered to satisfy a variety of demands from customers. The system considers the energy flow and energy loss regarding machine's age acceleration and their maintenance and its related hazardous energy. Hazardous energy is defined as 'any electrical, mechanical, hydraulic, pneumatic, chemical, nuclear, thermal, gravitational, or other energy that can harm personnel' [19]. For instances, chemical energy is the energy released when a substance undergoes a chemical reaction; Thermal energy is energy from an explosion, flame, objects with high or low temperatures or radiation from heat sources, etc.

In this context, the system is designed to generate a process plan while diagnosing energy loss and assigning preventive maintenance activities related to reliability reduction of system components. To take this into consideration -i.e. the correlation of process plan and maintenance activities - a mixed-integer non-linear problem (MINLP) is proposed. Moreover, the following assumptions are considered to decrease the complexity of problem:

1. A single production period is considered.

2. Maintenance activities will be planned at the end of processing time of each machine.

3. A continuous conveyor is assumed as a material handling system.

Fig. 1 presents the architecture of the studded RMS, where two units, respectively $\mathrm{P} 1$ and $\mathrm{P} 2$, are manufactured following three stages. As we can see, P1 will use machines M13, M21 and M32, where P2 will use machines M12, M22 and M31 respectively.

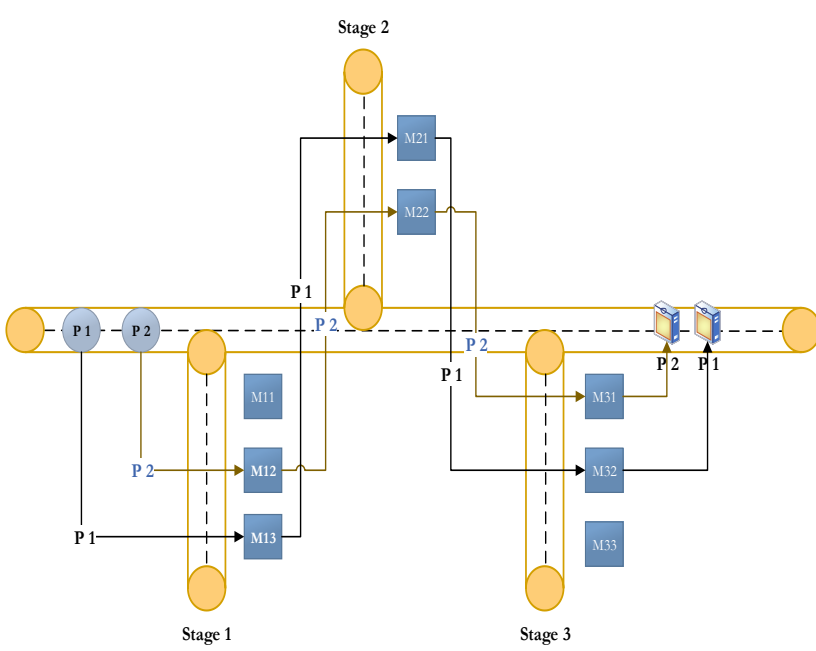

Fig. 1. Architecture of a reconfigurable manufacturing system. 


\section{B. Mathematical formulation}

As highlighted previously, a mixed-integer non-linear program (MINLP) is proposed in this section. Once we can fix the complicating decision variables, it will be possible to make decisions in the remaining problem independently. Table1 presents the used notations.

\section{TABLE I Notations}

\begin{tabular}{|c|c|}
\hline Sets & \\
\hline$P$ & Set of parts \\
\hline$O$ & Set of operations \\
\hline$M_{S}$ & Set of machine tools in ths $s^{\text {th }}$ stage \\
\hline$T$ & Set of tools \\
\hline \multicolumn{2}{|c|}{ Indices and Parameters } \\
\hline$p$ & Part index \\
\hline$i$ & Operation index \\
\hline$m, m^{\prime}$ & Machine tool index \\
\hline$t, t^{\prime}$ & Tool index \\
\hline$C T t_{m, t, t \prime}$ & $\begin{array}{l}\text { Changing time from tool } t \text { to } t^{\prime} \text { on } m^{\text {th }} \\
\text { machine }\end{array}$ \\
\hline$P t^{p, i}$ & $\begin{array}{l}\text { Processing time of the } \mathrm{i}^{\text {th }} \text { operation of the } \\
p^{\text {th }} \text { part }\end{array}$ \\
\hline$C T m_{m, m^{\prime}}$ & Changing time between machines $m$ and $m^{\prime}$ \\
\hline$E m, E t, E c$ & $\begin{array}{l}\text { Estimated hazardous energy related } \\
\text { respectively to machine, tools, and } \\
\text { conveyor maintenance activities }\end{array}$ \\
\hline R. (time). & $\begin{array}{l}\text { Reliability function of machines, tools, and } \\
\text { conveyor over time }\end{array}$ \\
\hline Mt. (time). & $\begin{array}{l}\text { Maintenance time of machines, tools, and } \\
\text { conveyor over usage time }\end{array}$ \\
\hline$M M d, T M d, C M d$ & $\begin{array}{l}\text { Expected maintenance time regarding } \\
\text { usage time of machines, tools, and } \\
\text { conveyer }\end{array}$ \\
\hline EL. (time). & $\begin{array}{l}\text { Energy loss function of machines, tools, } \\
\text { and conveyor over time }\end{array}$ \\
\hline$\theta$ & Accepted threshold for reliability \\
\hline \multicolumn{2}{|l|}{ Decision variables } \\
\hline$T i_{m}, T i_{t}, T c$ & $\begin{array}{l}\text { Usage time of respectively the } m^{\text {th }} \text { machine, } \\
\text { the } t^{\text {th }} \text { tool, and of convoyor }\end{array}$ \\
\hline$M t m, M t t, M t c$ & $\begin{array}{l}\text { Total maintenance time of machines, tools, } \\
\text { and conveyor }\end{array}$ \\
\hline$w_{m, t, t \prime}$ & $\begin{array}{l}1 \text { if the } m^{\text {th }} \text { change from tool } t \text { to } t^{\prime}, 0 \\
\text { otherwise }\end{array}$ \\
\hline$x_{m, t}^{p, i}$ & $\begin{array}{l}1 \text { if } i^{\text {th }} \text { operation of } p^{\text {th }} \text { part is using } m^{\text {th }} \\
\text { machine with } t^{\text {th }} \text { tool, } 0 \text { otherwise }\end{array}$ \\
\hline$y_{m, m \prime}$ & $\begin{array}{l}1 \text { if there is a change from machine } m \text { to } \\
\text { machine } m^{\prime}, 0 \text { otherwise }\end{array}$ \\
\hline$z m_{m}$ & $\begin{array}{l}1 \text { if the } m^{\text {th }} \text { machine needs maintenance } \\
\text { activity, } 0 \text { otherwise }\end{array}$ \\
\hline$z t_{t}$ & $\begin{array}{l}1 \text { if the } t^{\text {th }} \text { tool requires maintenance } \\
\text { activity, } 0 \text { otherwise }\end{array}$ \\
\hline$z c$ & $\begin{array}{l}1 \text { if conveyor requires maintenance activity, } \\
0 \text { otherwise }\end{array}$ \\
\hline
\end{tabular}

$$
\begin{aligned}
& \operatorname{Min}(T E L)=\sum_{m \in M}\left(E L_{m}\left(T i_{m}\right)\right)+E m * M t m \\
& +\sum_{t \in T}\left(E L_{t}\left(T i_{t}\right)\right)+E t * M t t \\
& +\left(E L_{c}(T c)+E c * M t c\right)
\end{aligned}
$$

Subject to:

$$
\begin{aligned}
& \sum_{\mathrm{m} \in \mathrm{M}} \sum_{\mathrm{t} \in \mathrm{T}} x_{m, t}^{p, i}=1, \forall p \in P, \forall i \in O \\
& \sum_{m \in M}^{\mathrm{m} \in \mathrm{M}} \sum_{t \in T}^{\mathrm{t} \in \mathrm{T}} x_{m, t}^{p, i+1} \leq \sum_{m \in M} \sum_{t \in T} x_{m, t}^{p, i}, \forall p \in P \\
& \sum_{p \in P} \sum_{i \in O} \sum_{t \in T} x_{m, t}^{p, i} * P t^{p, i} \\
& +\sum_{t \in T} \sum_{t^{\prime} \in T} w_{m, t, t \prime} * C T t_{m, t, t \prime}=T i_{m} \quad, \forall m \in M \\
& \sum_{p \in P} \sum_{i \in O} x_{m, t}^{p, i} * P t^{p, i}=T i_{t}, \forall m \in M, \forall t \in T \\
& \sum_{m \in M} \sum_{m \prime \in M} C T m_{m, m^{\prime}} * y_{m, m^{\prime}}=T c \\
& \left(1+z m_{m}\right) * R_{m}\left(T i_{m}\right) \geq \theta, \forall m \in M \\
& \left(1+z t_{t}\right) * R_{t}\left(T i_{t}\right) \geq \theta, \forall t \in T \\
& (1+z c) * R_{c}(T c) \geq \theta \\
& \sum_{m \in M} z m_{m} * M M d_{m}\left(T i_{m}\right)=M t m \\
& \sum_{t \in T}^{m} z t_{t} * T M d_{t}\left(T i_{t}\right)=M t t \\
& z c * C M d(T c)=M t c \\
& x_{m, t}^{p, i}, y_{m, m^{\prime}}, w_{m, t, t^{\prime}}, z m_{m}, z t_{t}, z c \in\{0,1\}
\end{aligned}
$$

Equation (1) represents the system energy loss due to age acceleration of components and energy consumption regarding maintenance activities. In this equation energy loss of machines, tools, and conveyor in the process plan are usage time functions of each components. Respectively, $E L_{m}\left(T i_{m}\right), E L_{t}\left(T i_{t}\right)$ and $E L_{c}(T c)$ are energy loss function related to machines, tools, and conveyor. Equation (2) ensures that each operation of each product is processed. Equation (3) ensures precedence constraints between operations. Equations (4)(6) calculate respectively the usage time of each machine, tools and conveyor (if machines change). Equations (7)(9) indicate that maintenance is needed for machines, tools, and conveyor if a reliability threshold is exceeded. Equations (10)-(12) compute the required maintenance time based on usage time of machines, tools, and conveyor. Correspondingly, maintenance time of machine tools, tools, and conveyor are associated with $\operatorname{MMd}\left(T i_{m}\right)$, $\operatorname{TMd}\left(T i_{t}\right), \operatorname{CMd}(T c)$. Equation (13) represents problem binary variables.

\section{BI-LEVEL LINEAR DECOMPOSITION APPROACH}

The complexity of our problem is tackled using a bilevel decomposition approach. The approach considers two levels: leader's level (upper-level) and follower's level (lower-level) [20]. The lower-level sub-problem is to generate a process plan according to the demanded parts by considering energy loss as objective i.e. generate an energy-friendly process plan. Where, the upper-level 
defines the second sub-problem (i.e. if the proposed solution in the previous level is feasible), which is to diagnose the reliability of selected machine and tools by the generated process plan in the lower-level. The Upperlevel also checks if a preventive maintenance is required due to the energy consumption related to the maintenance plan. Algorithm 1 defines the new parameters and variables between the two levels:

\section{Algorithm 1: Bi-level decomposition approach}

Input Data;

Set an empty archive;

Solve Min TEL(Total Energy Loss);

Generate a process plan; // (Lower-level)

Add $\left\{\right.$ Process $\quad$ plan; $\left.x_{m, t}^{p, i} ; y_{m, m,} ; w_{m, t, t} ; T i_{m} ; T i_{t} ; T c\right\}$ to archive ;

Add cuts $T i_{m}^{L} \leq T i_{m}, T i_{t}^{L} \leq T i_{t}, T c^{L} \leq T c$ as constraints;

Solve Min MEC (Maintenance energy consumption);// (Upperlevel)

\section{A. Solving lower-level sub-problem (Process planning)}

The objective of this lower-level is to generate an energy-friendly process plan. The resolution of this subproblem is guided by the minimization of the energy loss when using machines, tools and conveyor as shown in equation (14):

$$
\sum_{m \in M}^{\text {Min Energyloss }=} E L_{m}\left(T i_{m}\right)+\sum_{t \in T} E L_{t}\left(T i_{t}\right)+E L_{c}(T c)
$$

S.t. equations (2 to 6$)$.

\section{B. Solving upper-level sub-problem (System Diagnosis)}

This level checks first if the solution proposed in previous level is feasible. If it is the case we proceed to resolve the second sub-problem through a system diagnosis as shown in equation (15), which minimizes hazardous energy related to the maintenance plan.

Min $E m * M t_{m}+E t * M t_{t}+E c * M t_{c}$

$$
+ \text { Energyloss }{ }^{\text {optimal }}
$$

S.t. equations (7 to 12$)$ as well as

$$
\begin{aligned}
& z m_{m} \leq \sum_{p \in P} \sum_{i \in O} \sum_{t \in T} x_{m, t}^{p, i} \\
& z t_{t} \leq \sum_{p \in P} \sum_{i \in O} \sum_{t \in T} x_{m, t}^{p, i} \\
& z c \leq \sum_{m \in M} \sum_{m \prime \in M} y_{m, m \prime} \\
& T i_{m}^{L} \leq T i_{m} \\
& T i_{t}^{L} \leq T i_{t} \\
& T c^{L} \leq T c
\end{aligned}
$$

Equations (16)-(18) ensure that if machine tools, tools, and conveyor are used in lower-level, so maintenance might be required. Equations (19)-(21) represent usage time cuts obtained from lower-level.

\section{NUMERICAL EXAMPLE AND MODEL VALIDATION}

In this section, we propose an illustrative numerical example to validate the proposed model. We have two products to be manufactured with 3 operations each. The needed machine tools for these products are divided in three different stages $\left\{S_{1}, S_{2}\right.$, $\left.\mathrm{S}_{3}\right\}$ as shown in Figure 1. Moreover, for this example, we consider exponential distributions for EL.(time), R.(time), and Mt.(time). Following data represent ratios of energy loss $(\alpha)$, failure $(\beta)$, and age acceleration $(\gamma)$ for machine tools, tools, and conveyer, also related random inputs.

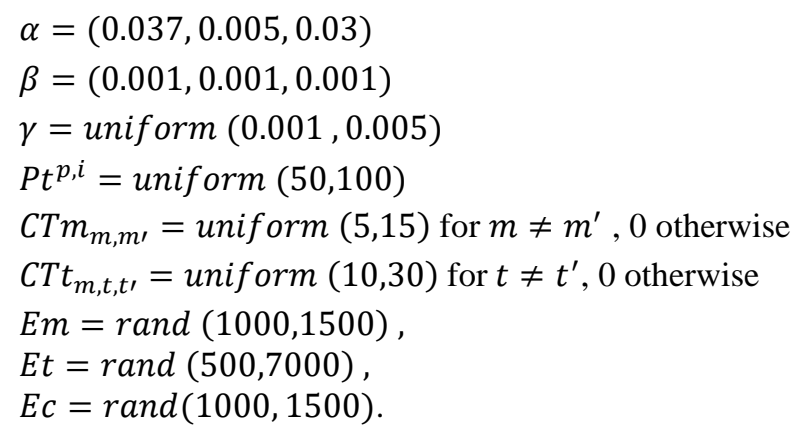

The problem is solved in two levels (i.e., lower and upper levels). The lower level considers process planning while assigning appropriate machines and tools to products and operations. This level is aimed to minimize the energy loss resulted from processing various operations. Table 2 represents the total working time of the selected machines and tools with their related energy loss.

TABLE 2. Working time and related energy loss (Lower level)

\begin{tabular}{|c|c|c|}
\cline { 2 - 3 } \multicolumn{1}{c|}{} & Total working time (min) & Energy loss \\
\hline Machines & 707 & 19297.07 \\
\hline Tools & 293 & 665.12 \\
\hline Conveyor & 74 & 9.21 \\
\hline & Total energy loss & $\mathbf{1 9 9 7 1 . 4}$ \\
\hline
\end{tabular}

The upper-level is proposed to diagnose the system functionality and if a preventive maintenance is required. In this level, the objective is to consume a minimum level of energy to perform the maintenance. The results obtained are given in Table 3.

TABLE 3. Upper-level resulted maintenance time and related energy consumption

\begin{tabular}{|c|c|c|}
\cline { 2 - 3 } \multicolumn{1}{c|}{} & $\begin{array}{c}\text { Total maintenance } \\
\text { time }\end{array}$ & $\begin{array}{c}\text { Maintenance energy } \\
\text { consumption }\end{array}$ \\
\hline Machines & 102 & 10200 \\
\hline Tools & 83 & 4565 \\
\hline Conveyor & 23 & 920 \\
\hline & Total energy loss & $\mathbf{1 5 6 8 5}$ \\
\cline { 2 - 3 } &
\end{tabular}


Table 4 illustrates the assigned machines following time, energy loss, reliability over processing time, and the consumed maintenance energy.

TABLE 4. Stage 1 obtained results

\begin{tabular}{|c|c|c|c|c|}
\hline Machine & Time & $\begin{array}{c}\text { Energy } \\
\text { loss }\end{array}$ & Reliability & $\begin{array}{c}\text { Maintenance } \\
\text { energy } \\
\text { consumption }\end{array}$ \\
\hline M11 & - & - & - & - \\
\hline M12 & 113 & 65.43 & 0.893 & 339 \\
\hline M13 & 123 & 94.73 & 0.884 & 369 \\
\hline
\end{tabular}

\section{CONCLUSION}

In this paper, we studied the problem of sustainable RMS design. We presented an attempt to integrate diagnosability and sustainability to design a sustainable RMS. First a mathematical formulation is proposed for this problem using a mixed-integer non-linear problem (MINLP). The model was solved in two steps through developing a bi-level decomposition approach. The lower level of this approach considers sustainable process plan generation by minimizing the energy loss that occurs during the production process (i.e. the use of selected machines, tools and conveyor). This level is followed by an Upper-level that diagnose the reliability of selected machine and tools by the generated process plan in the lower-level. The Upper-level also checks if a preventive maintenance is required due to the energy consumption related to the maintenance plan while minimizing hazardous energy related to it.

For future research perspectives, it will be interesting to explore the RMS sustainability by incorporating more of its core characteristics especially those related to system modularity, reconfiguration and scalability in order to study their impact on our model. Moreover, other aspect of sustainability should be also integrated in order to have a more comprehensive model that covers in depth each of the sustainability pillars.

\section{REFERENCES}

[1] H. A. ElMaraghy, "Reconfigurable process plans for responsive manufacturing systems", in Digital enterprise technology, pp. 35-44. Springer, 2007.

[2] I. Jawahir, F. Badurdeen, and K. Rouch, "Innovation in sustainable manufacturing education", Universitätsverlag der TU Berlin, 2015.

[3] Z. Bi, "Revisiting system paradigms from the viewpoint of manufacturing sustainability”, Sustainability 3(9), 13231340, 2011.

[4] GWPF: The global warming policy foundation, 2009, URL:https://www.thegwpf.org.

[5] A. Jayal, F. Badurdeen, O. Dillon Jr, and I. Jawahir, "Sustainable manufacturing: Modeling and optimization challenges at the product, process and system levels", CIRP Journal of Manufacturing Science and Technology 2(3), 144-152, 2010.

[6] Y. Koren, U. Heisel, F. Jovane, T. Moriwaki, G. Pritschow, G. Ulsoy, and H. Van Brussel, "Reconfigurable manufacturing systems", in Manufacturing Technologies for Machines of the Future, pp. 627-665. Springer Berlin Hezzidelberg, 1999.

[7] K. K. Goyal, P. Jain, and M. Jain, "Optimal configuration selection for reconfigurable manufacturing system using nsga ii and topsis", International Journal of Production Research 50(15), 4175-4191, 2012.

[8] O. Battaîa, A. Dolgui, and N. Guschinsky, "Decision support for design of reconfigurable rotary machining systems for family part production", International Journal of Production Research 55(5), 1368-1385, 2017.

[9] H. Haddou Benderbal, M. Dahane, and L. Benyoucef, "Modularity assessment in reconfigurable manufacturing system (rms) design: an archived multi objective simulated annealing-based approach", The International Journal of Advanced Manufacturing Technology 94(1-4), 729-749, 2018.

[10] S. Huang, G. Wang, X. Shang, and Y. Yan, "Reconfiguration point decision method based on dynamic complexity for reconfigurable manufacturing system (RMS)", Journal of Intelligent Manufacturing 29(5), 10311043, 2018.

[11] F. A. Touzout, L. Benyoucef, "Multi-objective sustainable process plan generation in a reconfigurable manufacturing environment: exact and adapted evolutionary approaches. International Journal of Production Research 57(8), 25312547 (2019).

[12] A. Khezri, H. Haddou Benderbal, and L. Benyoucef, "A sustainable reconfigurable manufacturing system designing with focus on environmental hazardous wastes", in 24th IEEE International Conference on Emerging Technologies and Factory Automation (ETFA). pp. 317-324, 2019.

[13] A. Kluczek, P. Olszewski, "Energy audits in industrial processes", Journal of cleaner production 142, 3437-3453, 2017.

[14] Y. Wang, Z. Ji, "Energy efficiency quantitative analysis method of discrete manufacturing system", Modern Physics Letters B 31(19-21), 1740071, 2017.

[15] D. M. Carabalí, C. R. Forero, and Y. Cadavid, "Energy diagnosis and structuring an energy saving proposal for the metal casting industry: An experience in Colombia", Applied Thermal Engineering 137, 767-773, 2018.

[16] A. Papetti, R. Menghi, G. Di Domizio, M. Germani, and M. Marconi, "Resources value mapping: A method to assess the resource efficiency of manufacturing systems", Applied Energy 249, 326-342, 2019.

[17] A. Khezri, H. Haddou Benderbal, and L. Benyoucef, "Sustainable multi-objective process plan generation in rms through modelling energy consumption", in Reconfigurable Manufacturing Systems: From Design to Implementation, pp. 161-177. Springer, 2020.

[18] A. Khezri, H. Haddou Benderbal, and L. Benyoucef, "Towards a sustainable reconfigurable manufacturing system (SRMS): multi-objective based approaches for process plan generation problem", International Journal of Production Research, 2020.

[19] T. C. Grover, "Highlights of the New ANSI/ASSE Z244. 1 Standard, Control of Hazardous Energy, Lockout/Tagout and Alternative Methods", in ASSE Professional Development Conference and Exposition. American Society of Safety Engineers, 2017.

[20] K. Lachhwani, A. Dwivedi, "Bi-level and multi-level programming problems: Taxonomy of literature review and research issues" Archives of Computational Methods in Engineering 25(4), 847-877, 2018. 